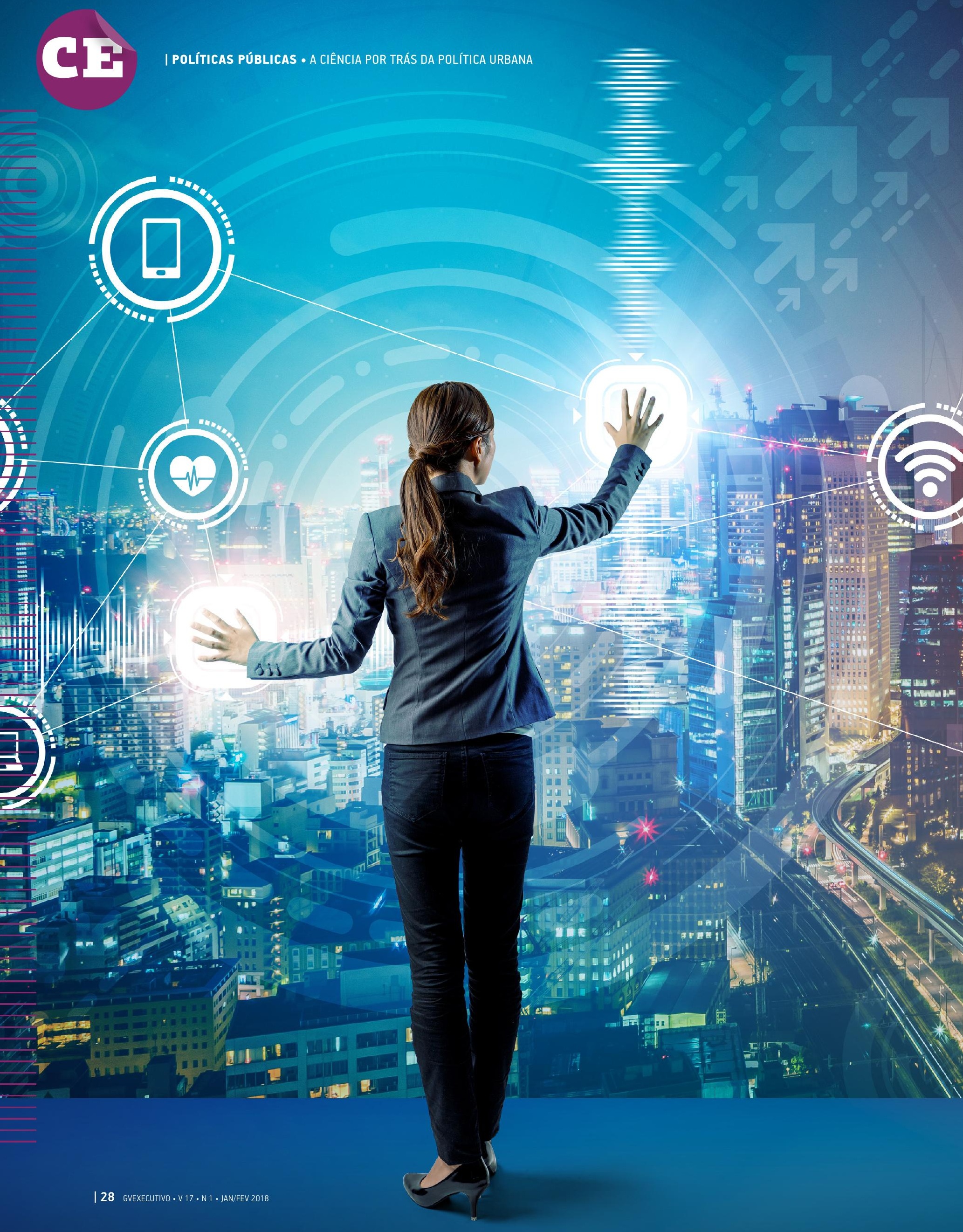




\section{A CIÊNCIA \\ POR TRÁS DA \\ POLÍTICA URBANA}

| POR CIRO BIDERMAN

\section{Quando os avanços no conhecimento se difundirem}

\section{entre as instituições e os indivíduos ligados direta ou indiretamente à gestão pública local, as cidades brasileiras poderão se tornar mais igualitárias e serão capazes de desempenhar o seu papel de liderança no país.}

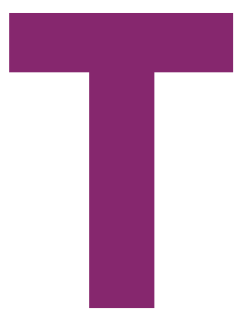

radicionalmente, os estudos urbanos caracterizaram-se, na sua versão mais aplicada, por ignorar a lógica econômica por trás das políticas públicas, a metodologia para se resolver problemas práticos e a política partidária e eleitoral. Os governos também têm, sistematicamente, desprezado os avanços do conhecimento científico na forma de fazer políticas públicas, sobretudo territoriais. No entanto, a política pública urbana não pode mais ser enfrentada apenas com intuição. No século XXI, ela precisa ser executiva se quiser, de fato, ser efetiva.

\section{DESENHO, IMPLEMENTAÇÃO E AVALIAÇÃO}

Uma política pública baseada em evidências deve começar com uma análise do que já foi feito em outros países, estados ou cidades. Em termos de questões urbanas, as cidades representam os casos mais relevantes. É possível desenvolver uma política totalmente nova, mas em geral há muito o que se aprender observando o que existe "por aí", ou, para usar o termo em inglês, realizando o benchmark da política em questão. Esse benchmark ajuda a realizar o primeiro desenho da política (ou programa) a ser proposta, a fazer uma análise do que se espera da política e a simular seus resultados potenciais. É também nessa fase que se desenvolve o marco lógico, sistema que exige que sejam definidos os objetivos, os indicadores, as metas e que, sobretudo, seja acompanhada a implementação da política ou do programa.

Um meio fundamental para desenhar as políticas públicas é o direito urbano. $\mathrm{O}$ direito é um aspecto transversal às políticas públicas urbanas, especialmente daquelas vinculadas às condições do território, como habitação, transporte, planejamento, segurança etc. As condições regulatórias 


\section{O MÍNIMO QUE UM GESTOR PRECISA SABER SOBRE AVALIAÇÃO DE POLÍTICAS PÚBLICAS:}

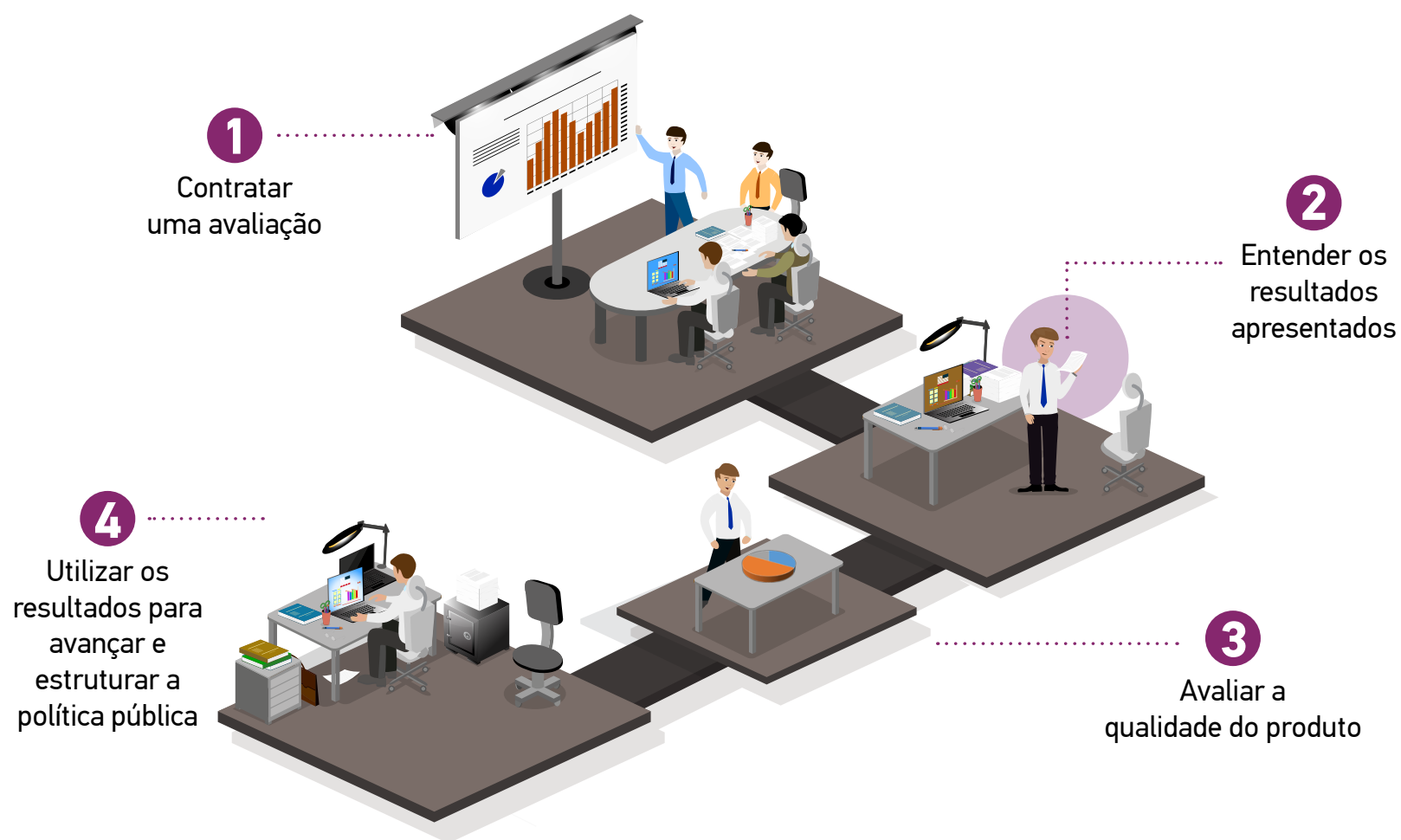

são uma variável de grande peso na hora de compreender as problemáticas vigentes e as possibilidades de mudança desde (e para) as políticas públicas. Incorporação de solo, zoneamento, uso e ocupação do solo, renovação e requalificação urbana, provisão e financiamento de suportes urbanos, proteção de componentes ambientais e com valor patrimonial coletivo, provisão de moradia social e cidade informal: todos esses temas têm elementos jurídicos que, se ignorados, inviabilizam a implementação de qualquer política pública urbana. Na prática, a implementação de uma política pública dá-se por meio de leis, decretos e portarias.

A fase de implementação é a que mais necessita de "métodos qualitativos". Esses métodos também são bastante úteis nos estudos de caso que compõem o benchmark, mas deveriam ser usados à exaustão na fase de implementação. Métodos qualitativos são particularmente atrativos em duas situações: quando o número de observações é pequeno e quando as perguntas de interesse são abertas, ou melhor, não há tanta precisão no que se pretende perguntar. Durante a implementação de uma política, é difícil saber o que dá certo ou errado a priori. Ou seja, entrevistas abertas nessa

\section{O ferramental necessário para} quem trabalha com políticas públicas locais inclui uma metodologia mista (quantitativa e qualitativa) e o conhecimento de áreas como economia urbana, análise espacial, inovação nas cidades, além da compreensão da política partidária e eleitoral local.

fase ajudam a formular as questões de interesse. Saber o que dá errado a tempo de corrigir o problema é algo de suma importância para garantir boas práticas no setor público.

A última fase de uma política pública baseada em evidências acontece na avaliação do impacto da política ou 
do programa. Essa fase é bem diferente da primeira, de avaliação a partir de simulações, pois ocorre após a implementação da política (e por isso é também denominada de "avaliação ex-post"). Nela, são requeridos métodos quantitativos. Uma ampla literatura ensina como avaliar o impacto social de políticas públicas, haja vista conhecimentos de estatística e econometria. Alguns estudiosos, bem como gestores públicos, acreditam que a avaliação de impacto ex-post deveria sempre ser realizada por uma instituição externa, para garantir sua independência, bem como para evitar conflitos de interesses. Mesmo considerada essa posição, e ainda que não seja o responsável pela avaliação, o gestor público precisa saber como fazer a avaliação de impacto social.

Assim, tanto gestores como estudiosos e estudantes da gestão pública que pretendem trabalhar na área, sem necessariamente serem servidores do Estado, precisam aprender sobre avaliação ex-post em sua formação. A maneira de aprender tudo isso, para fins aplicados, é fazendo. Estudantes de administração pública, seja de graduação, seja de pós-graduação, devem encarar um desafio real, tomando a política desde o início e seguindo-a até o fim. Na pesquisa aplicada, têm de ocupar funções consistentes com suas ambições de carreira e especialidades/capacidades.

Boa formação requer treino em situações reais ou análogas a elas, como simulações, pesquisa de campo, entrevistas e elaboração de notas, complementadas com uma boa formação em métodos quantitativos que possibilite avaliar o impacto das políticas. Esses elementos são fundamentais para que se adicione valor à implementação de políticas públicas urbanas para gestores, consultores, agências internacionais e organizações da sociedade civil em busca de melhores práticas no setor público. Ademais, como a política urbana ocorre no território, é especialmente importante o domínio de métodos especiais que permitam tratar o espaço com fundamentação teórica e orientação para a prática. O ideal para aumentar as chances de sucesso de uma política pública, portanto, é a utilização de ferramentas que misturem métodos quantitativos e métodos qualitativos, os chamados "métodos mistos". O quadro a seguir sintetiza essa ideia.

\section{FASES DA IMPLEMENTAÇÃO DE UMA POLÍTICA PÚBLICA BASEADA EM EVIDÊNCIAS}

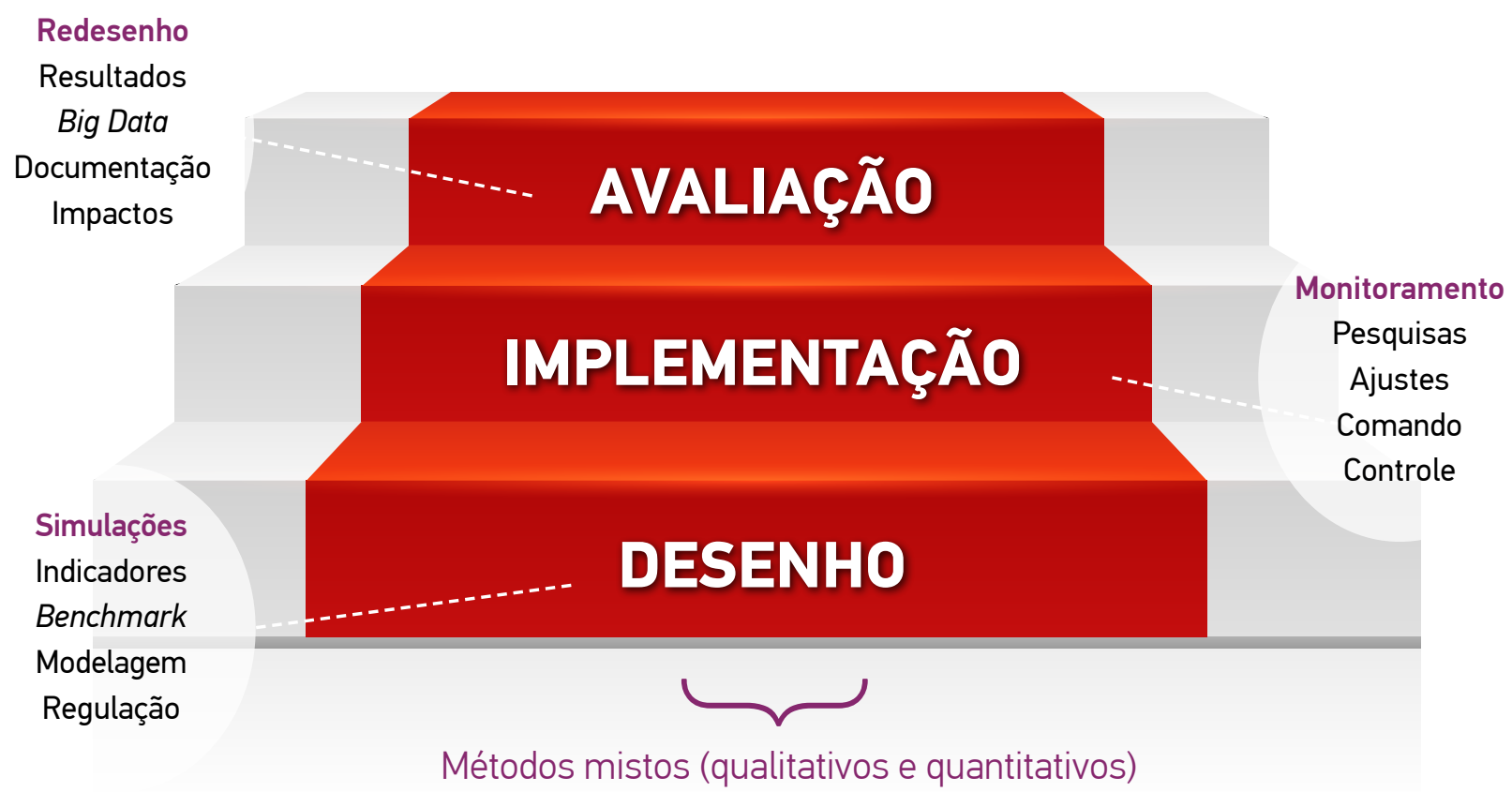



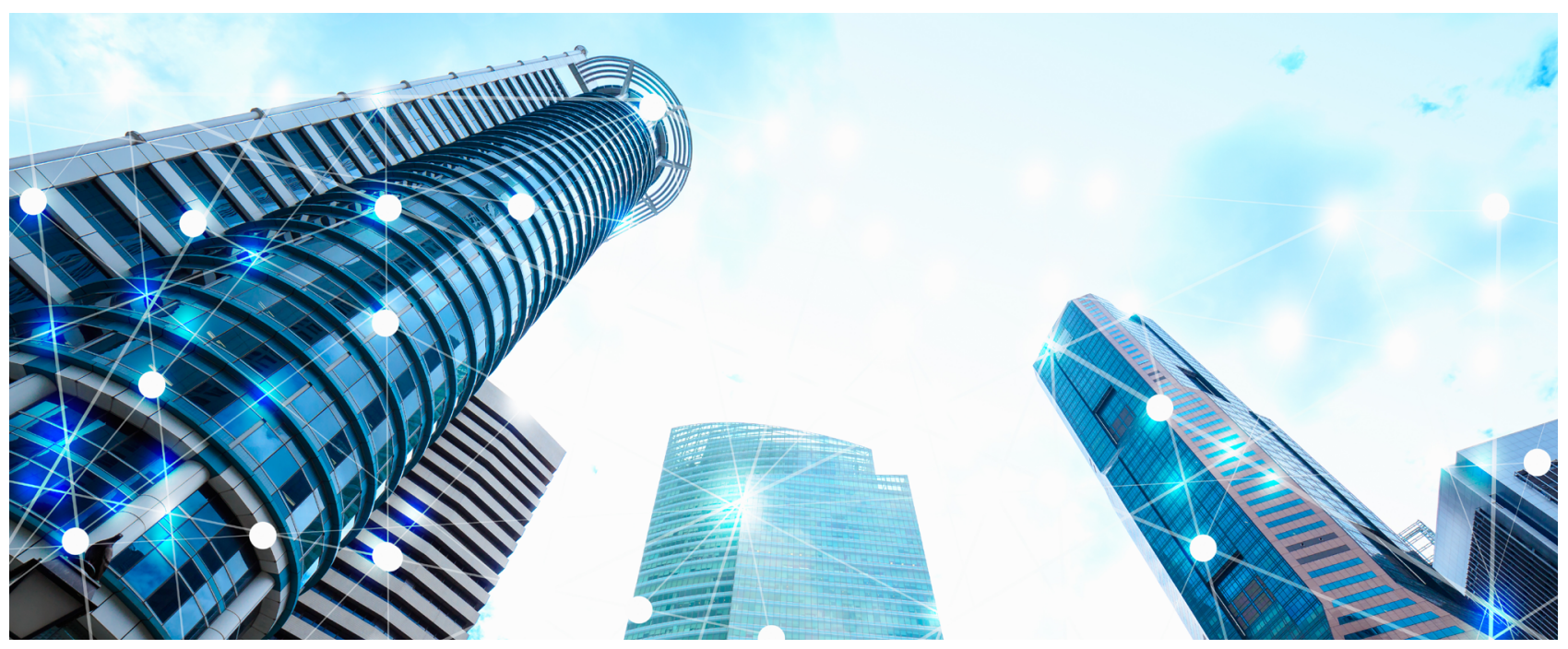

\section{OUTROS FATORES IMPORTANTES}

A construção crítica do instrumental analítico e propositivo daqueles que participam do processo de produção da cidade contemporânea é chave na melhoria da prática da política pública urbana, para o que é necessária uma visão integradora dos saberes específicos do planejamento e do projeto em direção à prática urbanística.

A política local também é um aspecto central do conhecimento que devem ter aqueles que atuam nas políticas públicas urbanas. Os governos municipais, não os governos nacionais ou estaduais, são aqueles com os quais os cidadãos interagem mais e que têm a maior influência na vida cotidiana. Na federação brasileira, os municípios são fonte de autoridade política e têm poder substancial em áreas como educação, saúde, desenvolvimento urbano e infraestrutura urbana, para citar as principais. Como se dá a ação municipal em uma democracia? Como acontece a relação com os outros níveis de governo, com o poder legislativo municipal e com o judiciário? Sem entender a política partidária e eleitoral, não é possível propor políticas públicas urbanas factíveis. Não queremos soluções técnicas maravilhosas que não "param em pé por causa dos políticos". O verdadeiro agente de mudança do setor público faz políticas que levam em conta como os políticos decidem.

Finalmente, não podemos esquecer que existe uma oportunidade aberta para as cidades e que precisa ser explorada. Os avanços nas tecnologias de informação e comunicação (TICs), que geraram fortunas para o setor privado nos últimos anos, precisam ser apropriados pelo setor público. Particularmente, se observarmos o perfil das inovações relevantes dos últimos anos, os serviços urbanos têm uma presença mais do que proporcional: Airbnb, Waze e Uber são alguns dos exemplos que deixam isso claro. Quais são as condições para a inovação aparecer e se difundir? Como Lagos, na Nigéria, conseguiu ser bem-sucedida em coletar impostos locais quando antes a arrecadação era nula? $\mathrm{Ou}$ como o sistema altamente oneroso de transporte público (veículo leve sobre trilhos, ou VLT) de Edimburgo não conseguiu melhorar a mobilidade de seus cidadãos?

\section{CONCLUSÃO}

Em suma, quem trabalha com políticas públicas locais precisa de um ferramental adicional ao já estabelecido. Esses instrumentos passam por uma metodologia mista (quantitativa e qualitativa), mas também por áreas que têm sido menos exploradas do que deveriam, como a economia urbana, o direito urbano, a análise espacial, a compreensão da política partidária e eleitoral local e a inovação nas cidades. Quando esse conhecimento se difundir entre as instituições e os indivíduos ligados direta ou indiretamente à gestão pública local, teremos uma nova geração de políticas urbanas mais condizentes com o século XXI, capazes de tornar as cidades mais igualitárias e de fazer com que elas desempenhem o seu papel de liderança no país.

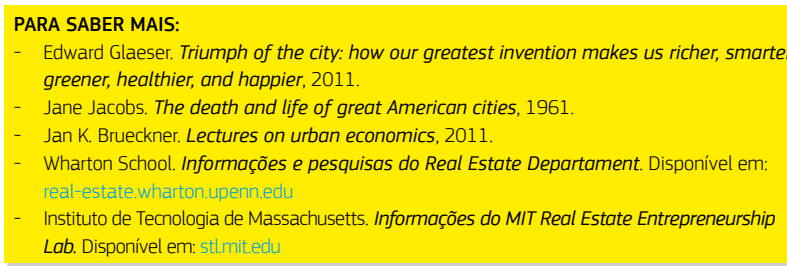

CIRO BIDERMAN > Professor da FGV EAESP > ciro.biderman@fgv.br 